\title{
Rapid screening of clarithromycin resistance in Helicobacter pylori by pyrosequencing
}

\author{
Correspondence \\ Karen-Anja Moder \\ karen.moder@med.ovgu.de \\ modek@gmx.de
}

Received 30 April 2007

Accepted 25 June 2007

\author{
Karen-Anja Moder, Franziska Layer, Wolfgang König and Brigitte König
}

Institute of Medical Microbiology, Otto-von-Guericke University Magdeburg, Leipziger Str. 44, 39120 Magdeburg, Germany

\begin{abstract}
Helicobacter pylori infections can be effectively treated with clarithromycin, a macrolide, in combination with other antibiotics, such as amoxicillin, tetracycline or metronidazole. The failure of $H$. pylori eradication is mainly associated with macrolide-resistant strains. Three point mutations (A2142G/C, A2143G, T2182C) in the peptidyltransferase region of domain $V$ of the $23 S$ rRNA have been described as being associated with clarithromycin resistance. Therefore, the determination of clarithromycin resistance by pyrosequencing was evaluated. $H$. pylori from 81 gastric biopsies was cultured and clarithromycin resistance was determined by Etest, as well as by pyrosequencing technology (PSQ 96 system; Biotage). The respective mutations were set in relation to the MIC measured in $\mu \mathrm{g} \mathrm{ml}^{-1}$ by Etest. In this study, point mutations in positions 2142 and 2143 were associated with clarithromycin resistance. Mutations in position 2182 did not contribute to clarithromycin resistance. In addition, from 22 out of the 81 biopsies, clarithromycin resistance was determined directly without culturing $H$. pylori to save additional time. Identical results were obtained as compared to resistance testing with pure $H$. pylori strains. All results obtained by pyrosequencing were evaluated by Sanger sequencing. The data show that pyrosequencing to detect point mutation is a fast and reliable method for determining clarithromycin resistance in $H$. pylori, and provides the same results as the Etest.
\end{abstract}

\section{INTRODUCTION}

Helicobacter pylori is a microaerophilic, Gram-negative bacterium that colonizes the human gastric mucosa. To eradicate $H$. pylori, a specific triple therapy is recommended as a first-line approach using a proton pump inhibitor (e.g. esomeprazole) in addition to antibiotics, such as clarithromycin/metronidazole or clarithromycin/amoxicillin (Treiber et al., 2005). Clarithromycin resistance is a major cause of treatment failure (Treiber et al., 2005; Toracchio et al., 2000; Fontana, 2003). Therefore, resistance testing should be considered before the first treatment.

H. pylori is a fastidious and slow-growing micro-organism. Therefore, standard cultures based on in vitro antibiotic susceptibility tests (agar dilution and Etest methods) are slow, and can take 7 to 14 days from initial receipt of the gastric specimen to reading and reporting the sensitivity results. Consequently molecular-based diagnostic assays for resistance detection offer an alternative approach for obtaining susceptibilities to antibiotics with higher speed and the possibility of a same-day result. Pyrosequencing has emerged as a new sequencing method. This technique is a widely applicable technology for the detailed characterization

Abbreviations: NPV, negative predictive value; PPV, positive predictive value; SNP, single nucleotide polymorphism. of nucleic acids and has been explained in detail (Ronaghi, 2000, 2001; Ronaghi et al., 1996, 1998, 1999). Pyrosequencing has the advantages of flexibility and parallel processing of the samples. Different studies have been performed to evaluate this specific method for detecting the antibiotic resistance of various micro-organism (Haanpera et al., 2005; Sinclair et al., 2003; Zhao et al., 2005).

Genetic research and studies have revealed that clarithromycin resistance can be associated with distinct mutations in either one or both copies of the H. pylori $23 \mathrm{~S}$ rRNA gene. Jiang et al. (1996) confirmed that the $H$. pylori genome carries just two copies of the $23 \mathrm{~S}$ rRNA gene. Versalovic et al. (1996) showed that point mutations in two positions (an adenine to guanine transition at either position 2142 or position 2143 , or an adenine to cytosine transversion at position 2142) in $23 \mathrm{~S}$ rRNA domain $V$ were associated with macrolide resistance. Point mutations at different additional sites have been described as occurring (Hultén et al., 1997), although these mutations have never been subsequently reported. Furthermore, a T2182C mutation has been proposed to be associated with high levels of clarithromycin resistance by Kim et al. (2002).

In this study we concentrated on the rapid detection of the three above described point mutations, which are essentially associated with clarithromycin resistance. The aim of 
this study was, therefore, to apply the pyrosequencing technique to DNA first extracted from cultured H. pylori strains, as well as directly from biopsy specimens, in order to obtain a result within a day of endoscopy.

\section{METHODS}

Gastric tissue. Gastric tissue was taken from 81 patients during gastric endoscopy examination (either from antrum or corpus). They were outpatients visiting the gastroenterology ambulance (outpatient clinic) or inpatients of the gastroenterology unit of the Otto-vonGuericke University Magdeburg. The outpatients were admitted into the ambulance for endoscopy by their general practitioner. A total of 16 samples were clinical isolates collected in a control study of patients included in a German surveillance study, the additional samples were from patients with chronic gastritis, peptic ulcer and gastric cancer. All patients were positive for the urea breath test and the antigen test in stool or urine. Immediately after endoscopy, the respective gastric biopsies were cultured on Pylori agar (bioMérieux). Plates were incubated for 3 to 7 days in a microaerobic atmosphere at $37{ }^{\circ} \mathrm{C}$ for primary culture. Every 2 to 3 days isolates were subcultured on the Pylori agar. Strains were identified as $H$. pylori by the use of standard criteria (Strobel et al., 1998; Kist, 1991). The remaining gastric biopsies were stored at $-80{ }^{\circ} \mathrm{C}$ until use, for example, in pyrosequencing.

Determination of MICs. MICs of clarithromycin were determined by Etest (AB Biodisk) on Iso-sensitest agar with $5 \%(\mathrm{w} / \mathrm{v})$ horse blood (Oxoid). The method was performed using the protocol of Heep et al. (2000), which is up to the standards of the DGHM (German Association for Hygiene and Microbiology) and the German reference centre for $H$. pylori. A sterile swab was dipped into the bacterial suspension equivalent to a McFarland standard of 2. After swabbing the entire plate surface with the inoculum, Etest strips impregnated with clarithromycin (concentration ranging from 0.016 to $256 \mu \mathrm{g} \mathrm{ml}^{-1}$ ) were placed on the agar surface. After an incubation period of 48 to $72 \mathrm{~h}\left(37{ }^{\circ} \mathrm{C}, 98 \%\right.$ humidity in microaerobic atmosphere), the MICs of clarithromycin were determined. Isolates were classified to be resistant to clarithromycin if the MIC exceeded $1 \mu \mathrm{g} \mathrm{ml}^{-1}$.

Isolation of genomic DNA. DNA from $H$. pylori isolates and from the biopsy samples was extracted using a QIAamp DNA mini kit (Qiagen).

Sanger sequencing of a part of the 23S rRNA gene. The primer pair DP1 and ZGE23 (Table 1) was used to amplify a 309 bp fragment of the peptidyltransferase region of the $23 \mathrm{~S}$ rRNA, as described by Taylor et al. (1997). The purified PCR products were sequenced with an ABI PRISM BigDye terminator v3.1 cycle sequencing kit (Applied Biosystems) according to the manufacturer's instructions. The PCR primers were used as sequencing primers. Sequencing was accomplished with an ABI PRISM 3100 genetic analyser (Applied Biosystems). The results were processed with Sequence Analysis Software (Applied Biosystems), and forward and reverse sequences were combined into a single consensus sequence with Assembler software (Applied Biosystems).

\section{Pyrosequencing}

PCR Amplification. Primers for PCR amplifications and pyrosequencing are listed in Table 1 . The two primers clal and cla8, and the sequencing primers seq1 and seq2, were designed with the PSQ assay design program (Assay Design software version 1.0.6; Biotage) based on an alignment of the $H$. pylori sequence (U27270) that was obtained from the National Center for Biotechnology Information. All amplifications were performed in a final volume of
Table 1. List of primers used for PCR amplification and pyrosequencing

\begin{tabular}{|lll|}
\hline Name & \multicolumn{1}{c|}{ Sequence $\left(\mathbf{5}^{\prime} \rightarrow \mathbf{3}^{\prime}\right)$} & Position $^{*}$ \\
\hline DP1 $\dagger$ & ACGGCGGCCGTAACTATA & $2357-2374$ \\
ZGE23 $\dagger$ & ACAGGCCAGTTAGCTA & $2649-2664$ \\
cla1 & ACGAGATGGGAGCTGTCTCAA & $2434-2454$ \\
cla8 & BIO-ATAAGAGCCAAAGCCCTTACTTC & $2589-2611$ \\
seq1 & ACCCGCGGCAAGACG & $2126-2140$ \\
seq2 & TTACTACAACTTAGCACTGC & $2159-2178$ \\
\hline
\end{tabular}

BIO, Biotin.

${ }^{\star}$ Numbering of the nucleotide position follows the system proposed by Taylor et al. (1997).

$\dagger$ Taylor et al. (1997).

$50 \mu \mathrm{l}$ containing both primers (clal and cla 8 ) at $2.0 \mu \mathrm{M}, 1 \mathrm{x}$ buffer, $800 \mu \mathrm{M}$ dNTP, $8 \mathrm{mM} \mathrm{MgCl}$, $1.25 \mathrm{U}$ Qiagen Taq polymerase, $10 \mathrm{ng}$ DNA-containing sample and HPLC-water to make up the volume. Conditions for cycling were $95{ }^{\circ} \mathrm{C}$ for $5 \mathrm{~min}$, followed by 45 cycles of $95{ }^{\circ} \mathrm{C}$ for $15 \mathrm{~s}, 54{ }^{\circ} \mathrm{C}$ for $30 \mathrm{~s}$ and $72{ }^{\circ} \mathrm{C}$ for $15 \mathrm{~s}$, and a final extension step at $72{ }^{\circ} \mathrm{C}$ for $5 \mathrm{~min}$.

Single-stranded template preparation and pyrosequencing. Singlestranded DNA template preparation was performed using streptavidincoated Sepharose beads (GE Healthcare, formerly Amersham Biosciences) and a vacuum prep tool (Pyrosequencing). All subsequent steps were performed according to the manufacture's instructions. The templates were transferred to a 96-well plate containing annealing solution (20 mM tris-acetate, $2 \mathrm{mM}$ magnesium acetate) and sequencing primers (seq1 and seq2) at $0.25 \mathrm{mM}$.

The PSQ96 plate was placed into the process chamber of a PSQ96MA instrument, and enzymes, substrates and nucleotides from the PyroGold reagent (Biotage) were dispensed. A charge-coupled device camera registered the light emitted from each incorporated nucleotide. The mutations A2142G and A2143G were analysed with the SQA (sequencing) mode (allows analysis of short sequences), while the mutation in position T2182C was analysed in SNP (single nucleotide polymorphism) mode (searches directly for given point mutations) of the PSA96MA software (version 2.1).

\section{RESULTS}

\section{Determination of MICs by Etest}

In this study 81 isolates of $H$. pylori were examined by Etest, and the clarithromycin MICs ranged from 0.016 to $256 \mu \mathrm{g} \mathrm{ml}^{-1}$ (Table 2). Etest identified 21 (25.9\%) strains as clarithromycin resistant and $60(74.1 \%)$ strains as clarithromycin susceptible (Table 2).

\section{Detection of point mutations in cultured $\boldsymbol{H}$. pylori strains}

Fig. 1 shows the DNA sequences, confirmed by Sanger sequencing and pyrosequencing, of wild-types $H$. pylori. Fig. 2 presents DNA sequences of $H$. pylori carrying the three mutations. Mutations were detected by pyrosequencing in $23(28.4 \%)$ of the respective isolates (Table 2). Nine 

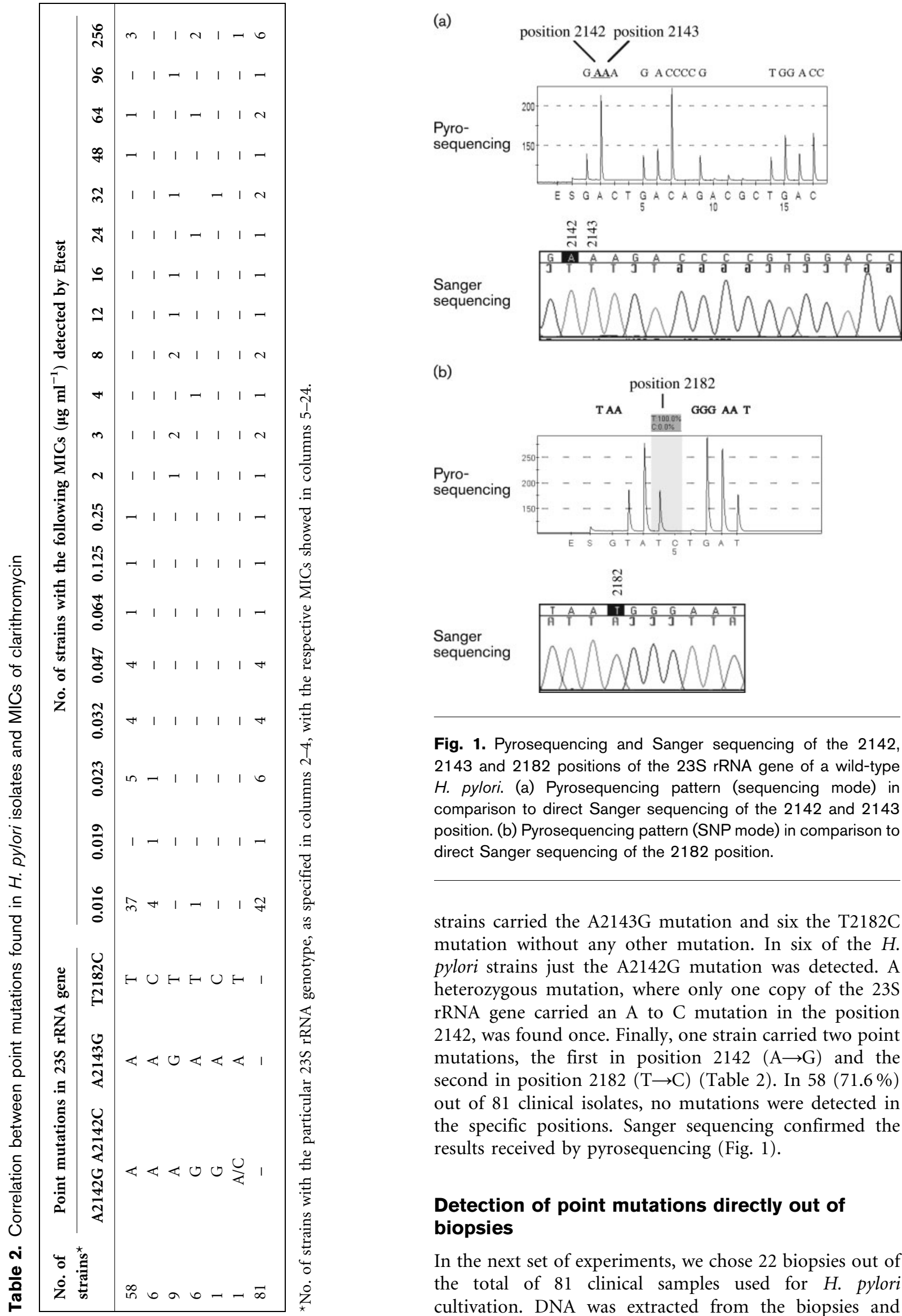

(b)
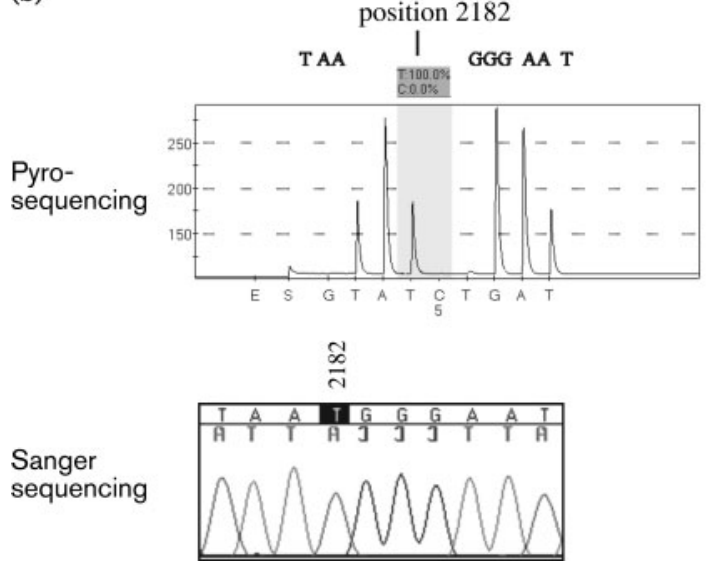

Fig. 1. Pyrosequencing and Sanger sequencing of the 2142 , 2143 and 2182 positions of the 23S rRNA gene of a wild-type $H$. pylori. (a) Pyrosequencing pattern (sequencing mode) in comparison to direct Sanger sequencing of the 2142 and 2143 position. (b) Pyrosequencing pattern (SNP mode) in comparison to direct Sanger sequencing of the 2182 position.

strains carried the A2143G mutation and six the T2182C mutation without any other mutation. In six of the $H$. pylori strains just the A2142G mutation was detected. A heterozygous mutation, where only one copy of the $23 \mathrm{~S}$ rRNA gene carried an A to $\mathrm{C}$ mutation in the position 2142 , was found once. Finally, one strain carried two point mutations, the first in position $2142(\mathrm{~A} \rightarrow \mathrm{G})$ and the second in position $2182(\mathrm{~T} \rightarrow \mathrm{C})$ (Table 2). In $58(71.6 \%)$ out of 81 clinical isolates, no mutations were detected in the specific positions. Sanger sequencing confirmed the results received by pyrosequencing (Fig. 1).

\section{Detection of point mutations directly out of biopsies}

In the next set of experiments, we chose 22 biopsies out of the total of 81 clinical samples used for $H$. pylori cultivation. DNA was extracted from the biopsies and 
(a)

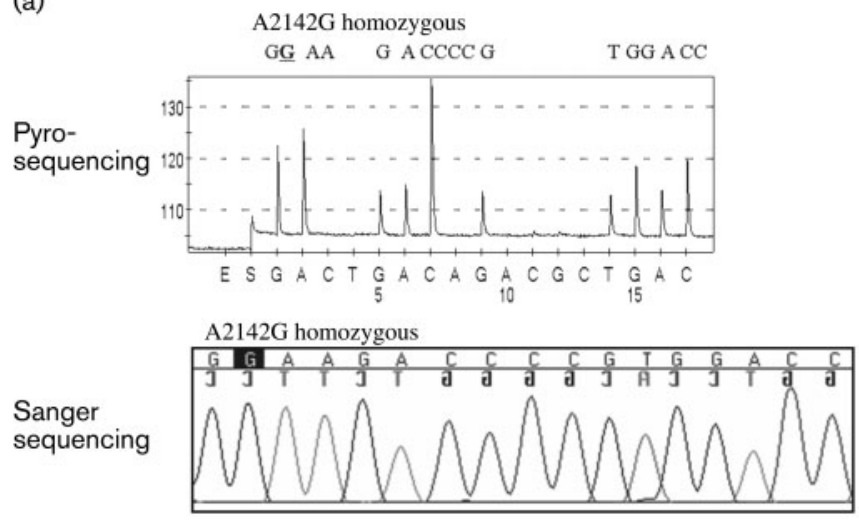

(b)

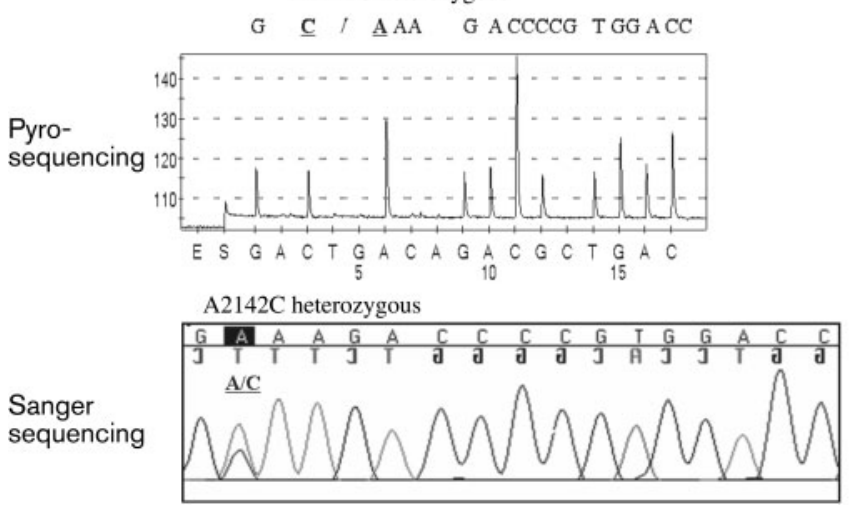

(c)

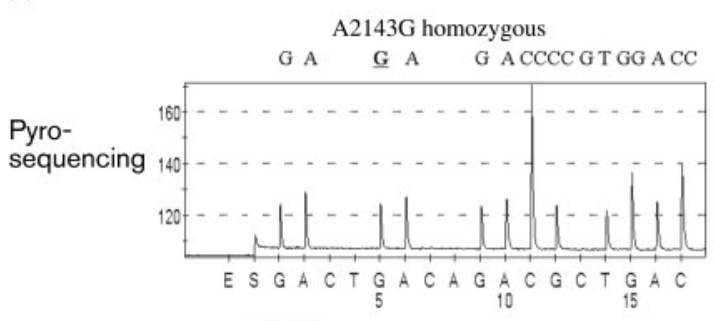

A2143G homozygous

Sanger sequencing

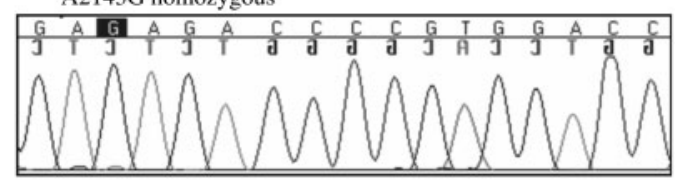

(d)

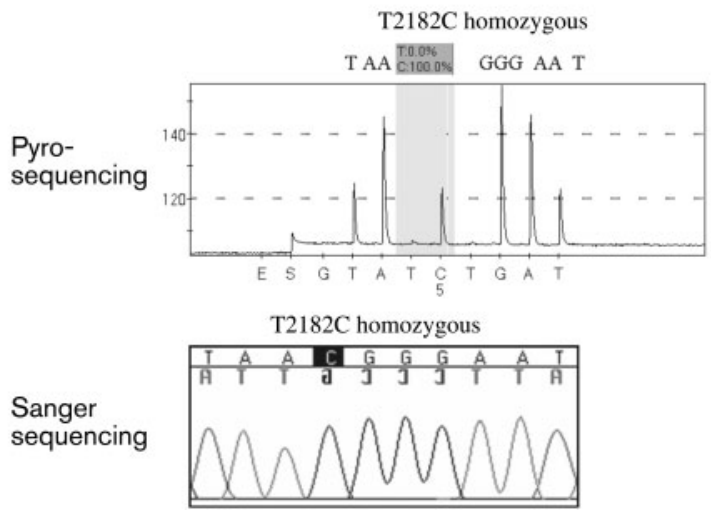

Fig. 2. Pyrosequencing and Sanger sequencing of the single point mutations at positions 2142,2143 and 2182 of the $23 S$ rRNA gene that are involved in clarithromycin resistance of $H$. pylori: (a) in position 2142 both alleles of the $23 S$ rRNA gene show an A to G mutation, (b) in position 2142 one allele shows an A to C mutation, (c) in position 2143 both alleles of the $23 S$ rRNA gene show an A to $G$ mutation, (d) in position 2182 both alleles of the $23 S$ rRNA gene show a $T$ to $C$ mutation.

pyrosequencing was applied with regard to clarithromycin resistance testing. All results derived directly from the clinical specimens without culturing $H$. pylori were identical to those derived from cultured $H$. pylori.

\section{Association of MIC and point mutations}

Out of 58 strains without SNP in the examined positions 53 were clarithromycin susceptible. The remaining five strains showed high MIC levels $\left[48 \mu \mathrm{g} \mathrm{ml}^{-1}(n=1) ; 64 \mu \mathrm{g}\right.$ $\left.\mathrm{ml}^{-1}(n=1) ; 256 \mu \mathrm{g} \mathrm{ml}^{-1}(n=3)\right]$.

With regard to position 2142, eight strains showed the respective point mutations and among them seven were defined as clarithromycin resistant [MIC: $4 \mu \mathrm{g} \mathrm{ml} \mathrm{ml}^{-1}$ $(n=1) ; 24 \mu \mathrm{g} \mathrm{ml}{ }^{-1} \quad(n=1) ; 32 \mu \mathrm{g} \mathrm{ml}{ }^{-1} \quad(n=1) ; 64 \mu \mathrm{g}$ $\left.\mathrm{ml}^{-1}(n=1) ; 256 \mu \mathrm{g} \mathrm{ml}{ }^{-1}(n=2)\right]$. All nine strains with SNPs in position 2143 were clarithromycin resistant [MIC: $2 \mu \mathrm{g} \mathrm{ml}^{-1}(n=1) ; 3 \mu \mathrm{g} \mathrm{ml}^{-1}(n=2) ; 8 \mu \mathrm{g} \mathrm{ml}^{-1}(n=2)$; $12 \mu \mathrm{g} \mathrm{ml}^{-1}(n=1) ; 16 \mu \mathrm{g} \mathrm{ml}^{-1}(n=1) ; 32 \mu \mathrm{g} \mathrm{ml}^{-1}(n=1)$; $\left.96 \mu \mathrm{g} \mathrm{ml}^{-1}(n=1)\right]$. The mutation in position 2182 was detected in seven isolates. However, among them, six strains were clarithromycin susceptible and only one strain showed clarithromycin resistance, MIC $256 \mu \mathrm{g} \mathrm{ml}^{-1}$. But in this particular strain an additional mutation in position 2142 was also found.

\section{Sensitivity, specificity, positive predictive value (PPV) and negative predictive value (NPV)}

Phenotypic resistance testing by agar dilution or Etest represents the gold standard. With the Etest used as the standard, pyrosequencing of the two point mutations at position 2142 and 2143 revealed a sensitivity/specificity of 75/98.3 \% and a PPV/NPV of 93.75/92.2\%.

\section{DISCUSSION}

The first-line therapy against $H$. pylori is primarily based on the use of clarithromycin in combination with either metronidazol or amoxicillin. In this regard, resistance to clarithromycin is an important predictor of treatment failure. Resistance to clarithromycin is reported to be about $3 \%$ in untreated patients and up to $50 \%$ after treatment failure. Among the H. pylori isolates in this study, $25.9 \%$ 
showed resistance against clarithromycin as determined by Etest. To circumvent clarithromycin resistance, some clinicians favour the high-doses combination using a proton pump inhibitor plus amoxicillin. However, eradication rates are only between 70 and $80 \%$, and side effects such as diarrhoea are more severe. Yahav et al. (2006) evaluated the efficacy of susceptibility-guided versus empiric retreatment for $H$. pylori after treatment failure, and determined the prevalence of post-treatment antibiotic resistance. Their results showed that susceptibility-guided retreatment appears to be significantly more effective than empiric retreatment in eradicating $H$. pylori after at least one previous treatment failure. Comparable results have been found by Kobayashi et al. (2006). Therefore, to use the optimal therapy for patients, a rapid and reliable resistance testing against clarithromycin would be helpful.

The gold standard for identification and susceptibility testing of $H$. pylori is still culture based, including agar dilution and Etest. However, H. pylori is a slow-growing micro-organism, so all these methods are time consuming. The introduction of molecular methods for $H$. pylori antibiotic-resistance testing has been consequently facilitated by the fact that the mode of action of clarithromycin is well understood and resistance is due to the described point mutations in the peptidyltransferase region of domain $\mathrm{V}$ of the $23 \mathrm{~S}$ rRNA gene. Therefore, molecularbased test methods were developed as an alternative approach. The basic assays were described 1996. Versalovic et al. (1996) first described the presence of the A2142G and A2143G mutations by PCR-RFLP. This method has been validated by direct sequencing as reported in many publications (Hultén et al., 1997; Occhialini et al., 1997; Szczebara et al., 1997; Versalovic et al., 1996). Alarcon et al. (2000), for instance, used a $3^{\prime}$ mismatched PCR to detect the A2142C mutation as a further method. In addition, a DNA enzyme immunoassay (Alarcon et al., 2000; Marais et al., 1999; Pina et al., 1998) was developed for directly screening gastric biopsies. The PCR line probe assay system (van Doorn et al., 2001) is an alternative way for testing large number of samples. Other more complex microtitre plate-based systems, such as the PCR oligonucleotide ligation assay using labelled capture and reporter probes, and the preferential homoduplex formation assay using double labelled amplicons, have also been applied to the detection of mutations but have not been generally evaluated. A recent and conceptually unique approach to the rapid detection of mutations was provided by the LightCycler realtime PCR hybridization assay. The sequencing method developed in 2001 based on pyrosequencing was used for rapid detection and identification of $H$. pylori in gastric specimens, and showed the potential for clarithromycin resistance typing of $H$. pylori. In this regard, Hjalmarsson et al. (2004) used pyrosequencing as a single technology to determine species identity, clarithromycin susceptibility and virulence level in cultured $H$. pylori strains, as well as directly from biopsies. In their study only $5 \mathrm{H}$. pylori strains out of a total of 146 were clarithromycin resistant. Thus they were not able to set the respective mutations in relation to the MIC measured in $\mu \mathrm{g} \mathrm{ml}^{-1}$ by Etest. Therefore, we extended their studies and developed assays for the detection of the respective point mutations (A2142G/C, A2143G, C2182T), which are, according to literature, associated with clarithromycin resistance. Our results were confirmed by Sanger sequencing, which is still the gold standard for mutation detection.

The relationship between the position of the mutation and phenotypic resistance against clarithromycin has been evaluated by different groups. Van Doorn et al. (2001) showed that the predominant mutations that are responsible for phenotypic clarithromycin resistance were A2143G and A2142G, the A2142C mutation was rare. Also strains containing a A2142T and A2143C where constructed and were clarithromycin resistant (Debets-Ossenkopp et al., 1998, 1999). Owen (2002) indicated that the $A 2142 \mathrm{G}$ mutation alone is associated with MICs $>256 \mu \mathrm{g} \mathrm{ml}^{-1}$. Regarding the outcome from our study, we can confirm these results only partially. We confirmed in this study that the point mutations in positions 2142 and 2143 are associated with clarithromycin resistance in accordance with previous studies. However, strains with the A2142G mutation alone $(n=6)$ expressed resistance at MICs of $4(n=1), 24(n=1)$, $64(n=1)$ and $256(n=2)$ or no resistance $(n=1)$. Whereas three clarithromycin-resistant strains with MIC levels $>256 \mu \mathrm{g} \mathrm{ml}^{-1}$ had no mutations at positions 2142,2143 and/or 2182. Further sequence analysis has to be done to detect additional mutations or resistance mechanisms associated with resistance to clarithromycin. Another controversial point is the stability of the point mutations leading to resistance. It is clear that if the mutations have a biological cost, they will not be maintained when selection pressure stops. Study groups claim that clarithromycin resistance is not stable over the long term (Xia et al., 1996). However, it is unlikely that in our study the strains (MIC levels >256) lost their point mutations. The respective strains were retested by Etest when the discrepant results became obviously. In a Korean study the T2182C mutants showed a tendency to have higher MIC levels for clarithromycin than the A2143G mutants (Kim et al., 2002). Khan et al. (2004) reported that a T2182C mutation in 23S rRNA is associated with clarithromycin resistance in $H$. pylori isolates obtained in Bangladesh. We could not confirm these findings. In our study a T2182C mutation by itself was not associated with clarithromycin resistance. Other mutations in the peptidyltransferase region of domain $\mathrm{V}$ of the $23 \mathrm{~S}$ rRNA are also described (A2115G, G2141A, T2717C), but are rarely found (Hultén et al., 1997). Fontana et al. (2002) found a $\mathrm{T}$ to $\mathrm{C}$ transition at position 2717 , which conferred a low level of resistance, equivalent to the MIC for the isolates. Thus, further investigations are necessary to determine additional mutations, which are responsible for clarithromycin resistance by themselves or in combination and differ from already described point mutations in the literature.

Assuming that phenotypic resistance testing by agar dilution or Etest represents the gold standard, molecular 
testing of the two point mutations at position 2142 and 2143 revealed a sensitivity/specificity of $75 / 98.3 \%$, and a PPV/NPV of $93.75 / 92.2 \%$. The results, derived from culturing $H$. pylori first, were compared to the results from the direct biopsy work up and showed identical findings. In summary, the pyrosequencing approach is a fast and reliable method that produces highly accurate results with regard to clarithromycin resistance as well as to other characteristics that are important for $H$. pylori therapy (Hjalmarsson et al., 2004).

\section{REFERENCES}

Alarcon, T., Domingo, D., Prieto, N. \& Lopez-Brea, M. (2000). PCR using $3^{\prime}$-mismatched primers to detect A2142C mutation in $23 \mathrm{~S}$ rRNA conferring resistance to clarithromycin in Helicobacter pylori clinical isolates. J Clin Microbiol 38, 923-925.

Debets-Ossenkopp, Y. J., Brinkman, A. B., Kuipers, E. J., Vandenbroucke-Grauls, C. M. J. E. \& Kusters, J. G. (1998). Explaining the bias in the 23S rRNA gene mutations associated with clarithromycin resistance in clinical isolates of Helicobacter pylori. Antimicrob Agents Chemother 42, 2749-2751.

Debets-Ossenkopp, Y. J., Herscheid, A. J., Pot, R. G., Kuipers, E. J., Kusters, J. G. \& Vandenbroucke-Grauls, C. M. (1999). Prevalence of Helicobacter pylori resistance to metronidazole, clarithromycin, amoxycillin, tetracycline and trovafloxacin in The Netherlands. J Antimicrob Chemother 43, 511-515.

Fontana, C., Favaro, M., Minelli, S., Criscuolo, A. A., Pietroiusti, A., Galante, A. \& Favalli, C. (2002). New site of modification of $23 \mathrm{~S}$ rRNA associated with clarithromycin resistance of Helicobacter pylori clinical isolates. Antimicrob Agents Chemother 46, 3765-3769.

Fontana, C., Favaro, M., Pietroiusti, A., Pistoia, E. S., Galante, A. \& Favalli, C. (2003). Detection of clarithromycin-resistant Helicobacter pylori in stool samples. J Clin Microbiol 41, 3636-3640.

Haanpera, M., Huovinen, P. \& Jalava, J. (2005). Detection and quantification of macrolide resistance mutations at positions 2058 and 2059 of the $23 \mathrm{~S}$ rRNA gene by pyrosequencing. Antimicrob Agents Chemother 49, 457-460.

Heep, M., Kist, M., Strobel, S., Beck, D. \& Lehn, N. (2000). Secondary resistance among 554 isolates of Helicobacter pylori after failure of therapy. Eur J Clin Microbiol Infect Dis 19, 538-541.

Hjalmarsson, S., Alderborn, A., Fock, C., Muldin, I., Kling, H., Uhlén, M. \& Engstrand, L. (2004). Rapid combined characterization of microorganism and host genotypes using a single technology. Helicobacter $\mathbf{9}$, 138-145.

Hultén, K., Gibreel, A., Sköld, O. \& Engstrand, L. (1997). Macrolide resistance in Helicobacter pylori: mechanism and stability in strains from clarithromycin-treated patients. Antimicrob Agents Chemother 41, 2550-2553.

Jiang, Q., Hiratsuka, K. \& Taylor, D. E. (1996). Variability of gene order in different Helicobacter pylori strains contributes to genome diversity. Mol Microbiol 20, 833-842.

Khan, R., Nahar, S., Sultana, J., Ahmad, M. M. \& Rahman, M. (2004). T2182C mutation in 23S rRNA is associated with clarithromycin resistance in Helicobacter pylori isolates obtained in Bangladesh. Antimicrob Agents Chemother 48, 3567-3569.

Kim, K. S., Kang, J. O., Eun, C. S., Han, D. S. \& Choi, T. Y. (2002). Mutations in the 23S rRNA gene of Helicobacter pylori associated with clarithromycin resistance. J Korean Med Sci 17, 599-603.
Kist, M. (1991). Diagnostische Verfahrensrichtlinien der DGHM: Isolierung und Identifizierung von Bakterien der Gattungen Campylobacter und Helicobacter. Zentralbl Bakteriol 276, 124-139.

Kobayashi, I., Saika, T., Muraoka, H., Murakami, K. \& Fujioka, T. (2006). Helicobacter pylori isolated from patients who later failed $H$. pylori eradication triple therapy readily develop resistance to clarithromycin. J Med Microbiol 55, 737-740.

Marais, A., Monteiro, L., Occhialini, A., Pina, M., Lamouliatte, H. \& Megraud, F. (1999). Direct detection of Helicobacter pylori resistance to macrolides by a polymerase chain reaction DNA enzyme immunoassay in gastric biopsy specimens. Gut 44, 463-467.

Occhialini, A., Urdaci, M., Doucet-Populaire, F., Bebear, C. M., Lamouliatte, H. \& Megraud, F. (1997). Macrolide resistance in Helicobacter pylori: rapid detection of point mutations and assays of macrolide binding to ribosomes. Antimicrob Agents Chemother 41, 2724-2728.

Owen, R. J. (2002). Molecular testing for antibiotic resistance in Helicobacter pylori. Gut 50, 285-289.

Pina, M., Occhialini, A., Monteiro, L., Doermann, H. P. \& Megraud, F. (1998). Detection of point mutations associated with resistance of Helicobacter pylori to clarithromycin by hybridization in liquid phase. J Clin Microbiol 36, 3285-3290.

Ronaghi, M. (2000). Improved performance of pyrosequencing using single-stranded DNA-binding protein. Anal Biochem 286, 282-288.

Ronaghi, M. (2001). Pyrosequencing sheds light on DNA sequencing. Genome Res 11, 3-11.

Ronaghi, M., Karamohamed, S., Pettersson, B., Uhlen, M. \& Nyren, P. (1996). Real-time DNA sequencing using detection of pyrophosphate release. Anal Biochem 242, 84-89.

Ronaghi, M., Uhlen, M. \& Nyren, P. (1998). A sequencing method based on real-time pyrophosphate. Science 281, 363-365.

Ronaghi, M., Nygren, M., Lundeberg, J. \& Nyren, P. (1999). Analyses of secondary structures in DNA by pyrosequencing. Anal Biochem 267, 65-71.

Sinclair, A., Arnold, C. \& Woodford, N. (2003). Rapid detection and estimation by pyrosequencing of $23 \mathrm{~S}$ rRNA genes with a single nucleotide polymorphism conferring linezolid resistance in enterococci. Antimicrob Agents Chemother 47, 3620-3622.

Strobel, S., Bereswill, S., Balig, P., Allgaier, P., Sonntag, H. G. \& Kist, M. (1998). Identification and analysis of a new vacA genotype variant of Helicobacter pylori in different patient groups in Germany. J Clin Microbiol 36, 1285-1289.

Szczebara, F., Dhaenens, L., Vincent, P. \& Husson, M. O. (1997). Evaluation of rapid molecular methods for detection of clarithromycin resistance in Helicobacter pylori. Eur J Clin Microbiol Infect Dis 16, 162-164.

Taylor, D. E., Ge, Z., Purych, D., Lo, T. \& Hiratsuka, K. (1997). Cloning and sequence analysis of two copies of a $23 \mathrm{~S}$ rRNA gene from Helicobacter pylori and association of clarithromycin resistance with $23 \mathrm{~S}$ rRNA mutations. Antimicrob Agents Chemother 41, 2621-2628.

Toracchio, S., Cellini, L., Di Campli, E., Cappello, G., Malatesta, M. G., Ferri, A., Ciccaglione, A. F., Grossi, L. \& Mario, L. (2000). Role of antimicrobial susceptibility testing on efficacy of triple therapy in Helicobacter pylori eradication. Aliment Pharmacol Ther 14, 1639-1643.

Treiber, G., Kist, M., Klotz, U., Peitz, U. \& Malfertheiner, P. (2005). Therapie der Helicobacter-pylori-infektion: klinische, mikrobiologische und pharmakologische Aspekte. Dtsch Arztebl 26, 1883-1888.

van Doorn, L. J., Glupczynski, Y., Kusters, J. G., Megraud, F., Midolo, P., Maggi-Scola, N., Queiroz, D. M., Nouhan, N., Stet, E. \& Quint, W. G. 
(2001). Accurate prediction of macrolide resistance in Helicobacter pylori by a PCR line probe assay for detection of mutations in the $23 \mathrm{~S}$ rRNA gene: multicenter validation study. Antimicrob Agents Chemother 45, 1500-1504.

Versalovic, J., Shortridge, D., Kibler, K., Griffy, M. V., Beyer, J., Flamm, R. K., Tanaky, S. K., Graham, D. Y. \& Go, M. F. (1996). Mutations in $23 \mathrm{~S}$ rRNA are associated with clarithromycin resistance in Helicobacter pylori. Antimicrob Agents Chemother 40, 477-480.

Xia, H. X., Buckley, M., Keane, C. T. \& O’Morain, C. A. (1996). Clarithromycin resistance in Helicobacter pylori: prevalence in untreated dyspeptic patients and stability in vitro. I Antimicrob Chemother 37, 473-481.

Yahav, J., Samra, Z., Niv, Y., Evans, C. T., Passaro, D. J., Dinari, G. \& Shmuely, H. (2006). Susceptibility-guided vs. empiric retreatment of Helicobacter pylori infection after treatment failure. Dig Dis Sci 51, 2316-2321.

Zhao, J. R., Bai, Y. J., Zhang, Q. H., Wang, Y., Luo, M. \& Yan, X. J. (2005). Pyrosequencing-based approach for rapid detection of rifampin-resistant Mycobacterium tuberculosis. Diagn Microbiol Infect Dis 51, 135-137. 